\title{
Phonology in the bilingual Stroop effect
}

\author{
HIROMI SUMIYA and ALICE F. HEALY \\ University of Colorado, Boulder, Colorado
}

\begin{abstract}
In a bilingual Stroop task, we examined between-language interference among proficient JapaneseEnglish bilingual speakers. Participants named ink colors either in Japanese or in English. The Japanese color terms were either phonologically similar to (i.e., loan words) or dissimilar from (i.e., traditional color terms) English color terms. For both response languages, a significant between-language Stroop effect was found despite the orthographic dissimilarity between the languages. The magnitude of the between-language interference was larger with the phonologically similar terms. These findings implicate direct links connecting phonologically similar matching words in the lexicons of proficient bilingual speakers of dissimilar languages and imply that phonological processing in lexical access occurs even when the access is done unintentionally.
\end{abstract}

The Stroop effect is a well-known phenomenon of interference in a color-naming task first devised by Stroop (1935). Participants name the colors of the inks in which incongruent color words are printed (e.g., RED printed in blue ink) while ignoring the words. It takes participants significantly longer to name the ink colors when presented with incongruent color words than when presented with colored control stimuli (e.g., color patches). A generally accepted theoretical account is based on the unintentional (automatic) processing of the incongruent words by skilled readers (e.g., Posner \& Snyder, 1975).

A bilingual version of the Stroop task involves color terms from bilinguals' two languages as stimuli, with which the color naming task can be conducted in either the bilinguals' first language (L1) or their second language (L2). As a result, the bilingual Stroop test yields two types of interference: between-language (L1 word and L2 naming; L2 word and L1 naming) and within-language (L1 word and L1 naming; L2 word and L2 naming) interference (e.g., Dyer, 1971; Preston \& Lambert, 1969). The degrees of the Stroop effect observed in between- and within-language interference are considered to reflect the strength of connections both between L1 and L2, and between each language and the underlying concepts.

Several models of bilingual language representation have been proposed that take two hierarchical levels into

This research was supported in part by Army Research Institute Contracts DASW01-99-K-0002 and DASW01-03-K-0002 to the University of Colorado (A.F.H., principal investigator; Lyle E. Bourne, Jr., co-principal investigator). Support was also provided by an award from the Institute of Cognitive Science at the University of Colorado to H.S. This study was described in a paper at the 73rd Annual Convention of the Rocky Mountain Psychological Association in Denver, Colorado, on April 12, 2003. We are indebted to Bill Bonk for help testing the participants in Japan, to Lise Menn and Akira Miyake for very helpful comments about this research, and to Cynthia Dulaney, Avishai Henik, and Harvey Marmurek for helpful comments on an earlier version of this article. Correspondence may be addressed to A. F. Healy, Department of Psychology, 345 UCB, Boulder, CO 80309-0345 (e-mail: ahealy@psych.colorado.edu). consideration (see Figure 1): a lexical level, which consists of two distinct and independent lexicons, and a conceptual level, which is shared by the two languages (see, e.g., Kolers, 1966; Kroll, Michael, \& Sankaranarayanan, 1998; Kroll \& Stewart, 1994; Potter, So, Von Eckardt, \& Feldman, 1984). Whether and how the three components (i.e., L1, L2, and concepts) interact and how bilingual speakers access these three components continue to be issues to be resolved.

Between-language interference is approximately $75 \%$ of within-language interference (MacLeod, 1991). This ratio of between-language to within-language interference, however, has ranged from $22 \%$ to $140 \%$ (Francis, 1999). It has been suggested that the specific ratio is due to both the orthographic similarity between the two languages (e.g., Fang, Tzeng, \& Alva, 1981) and the proficiency of the bilingual speakers.

For instance, Potter et al. (1984) considered a word association hypothesis for bilinguals with low or intermediate proficiency and a concept mediation hypothesis for bilinguals with high proficiency. The word association hypothesis assumes that L2 learners access the meaning of L2 words only through their L1 (i.e., there are only links A and B in Figure 1). This model predicts that L1 color terms will yield more interference than L2 color terms regardless of response language. In contrast, the concept mediation hypothesis assumes that words in both L1 and L2 are directly connected to the conceptual representation (i.e., there are only links B and C in Figure 1). Thus, within-language interference should be greater than between-language interference regardless of the response language.

In addition, Chen and Ho (1986) proposed a mixed model after carrying out bilingual Stroop tasks among Chinese-English bilinguals of varying proficiency levels. (In describing bilinguals, we use the notation L1-L2.) They found that for all participants responding in L1, within-language interference was greater than betweenlanguage interference. Furthermore, when responding in 


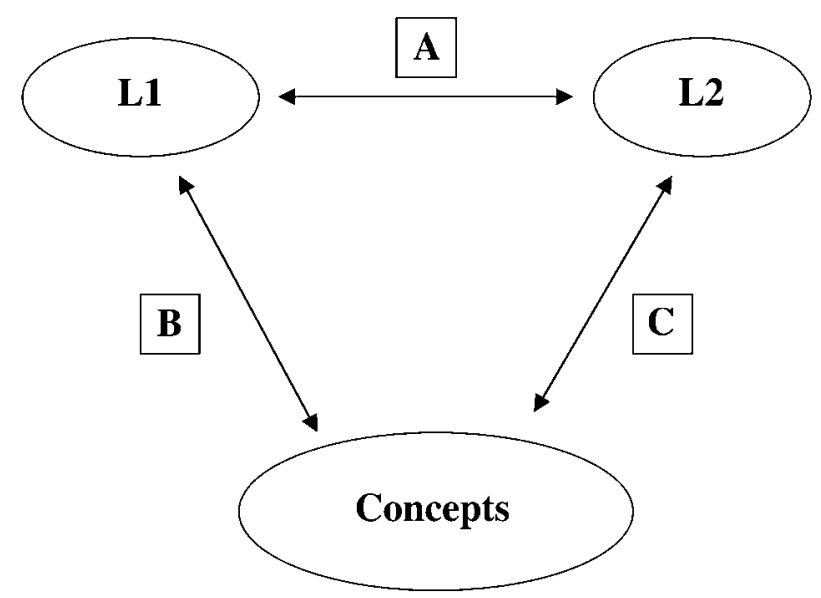

Figure 1. A schematic diagram of bilingual language representation. The word association model includes only the $A$ and $B$ links. The concept mediation model includes only the $B$ and $C$ links. The multiple access model includes all three links $(\mathrm{A}, \mathrm{B}$, and $\mathrm{C}$ ).

L2, participants with higher levels of proficiency showed more within-language interference, whereas participants with lower levels of proficiency experienced more betweenlanguage interference. Consequently, the mixed model includes the word association model for the beginning of L2 learning, with the concept mediation model gradually replacing the word association model as proficiency increases.

As Brauer (1998) has pointed out, however, the mixed model cannot explain the high degree of between-language interference among highly proficient bilinguals of very similar languages (e.g., the German-Swedish bilinguals studied by Mägiste, 1984). Thus, Brauer postulated a multiple access model, which includes all three links (A, $\mathrm{B}$, and $\mathrm{C}$ in Figure 1). The results from two experiments provided support for this model. The between-language interference among the highly proficient bilinguals of dissimilar language pairs (English-Greek and ChineseEnglish) was small, as compared with the within-language interference, whereas the highly proficient bilinguals of similar language pairs (English-German and GermanEnglish) experienced a similar degree of between-language and within-language interference.

To assess the importance of orthographic processing in the bilingual Stroop effect, Fang et al. (1981) conducted an experiment with Japanese-English bilinguals. The Japanese language provides an opportunity to examine how different orthographic systems, which involve different processing (Morikawa, 1981), influence bilinguals' language representation. Japanese orthography consists of the Kana and Kanji systems. Kanji is ideographic, whereas Kana is syllabic. The Kana system is further divided into Hiragana and Katakana. Hiragana is used mostly for grammatical particles, whereas Katakana is used for loan words (LWs), which are commonly used among the monolingual speech community. Shorter response times have been observed with Kana than with
Kanji in naming, which is considered to indicate the closer relation between Kana and phonological processing (Feldman \& Turvey, 1980).

In Fang et al.'s (1981) study, Japanese-English bilinguals were presented with traditional color terms, in a betweensubjects design, including Kanji/English or Hiragana/ English. There was greater within-language than betweenlanguage interference, especially with Kanji when participants named in Japanese, but between-language interference was evident in both groups. Importantly, the reduction in interference from within-language to betweenlanguage conditions did not differ significantly between the two groups. Because these different orthographies had similar effects when the phonology was held constant, the authors concluded that phonological factors contributed more than orthographic factors did.

A study by Tzelgov, Henik, Sneg, and Baruch (1996) provides additional evidence that phonological processing takes place in parallel to orthographic processing. They presented Hebrew-English bilinguals with crossscript homophones as the stimuli in a Stroop task. The cross-script homophones consisted of nonword stimuli that were words in one language when pronounced (e.g., Hebrew) but were written in the script of the other language (e.g., English). The cross-script homophones were orthographically unfamiliar to the participants (e.g., kahol written in the Roman alphabet is unfamiliar but sounds like the Hebrew word for blue). Nevertheless, in some cases in which the cross-script homophones had meaning in Hebrew, they produced just as large a Stroop effect as did the color terms written in Hebrew. This result implies that Stroop interference depends on the phonological familiarity of the stimuli, rather than on their orthographic familiarity.

On the basis of this implication, we hypothesize that an increase in the phonological similarity of a dissimilar language pair could enhance the magnitude of the betweenlanguage Stroop effect. Japanese offers a unique opportunity to test this hypothesis by using Katakana LWs. Specifically, color terms in LWs that are originally from English are used as Japanese responses-[g.si:n] (グリーン, “green”), [b.ru:] (ブルー, “blue”), and [..ed าdo] (レッド, "red") — and are compared with the traditional color terms (TCTs): [midosi] (みどり, “green”), [ao] (あお, “blue”), and [aka] (あか, "red") (see Table 1). The Japanese and English words are phonologically similar in the case of the LWs but are dissimilar in the case of the TCTs.

Katakana orthography maintains the dissimilarity to English while increasing the phonological similarity. If phonological processing takes place upon orthographic processing, the dissimilarity between English and Japanese should be reduced by the phonological similarity between English and LWs. This reasoning leads to the prediction of larger between-language interference involving either responding in LWs to English stimuli or responding in English to Katakana stimuli.

The present study involved a two-part experiment in which the Stroop task was used. The parts were identical in design, with one important exception: All responses 
Table 1

Word and Control Stimuli of Three Orthographies

\begin{tabular}{|c|c|c|c|}
\hline $\begin{array}{l}\text { Three Types of } \\
\text { Orthographies }\end{array}$ & \multicolumn{3}{|c|}{ Color Words and Control Stimuli } \\
\hline \multirow[t]{2}{*}{ English } & blue & red & green \\
\hline & ... & ... & .... \\
\hline \multirow[t]{2}{*}{ Katakana (LWs) } & ブルー & レッド & グリーン \\
\hline & $\ldots$ & $\ldots$ & $\ldots$ \\
\hline \multirow[t]{2}{*}{ Hiragana (TCTs) } & あお & あか & みどり \\
\hline & $\bullet$ & $\bullet$ & •. \\
\hline
\end{tabular}

Note-LW, loan word; TCT, traditional color term.

were in Japanese in the first part but were in English in the second part. Note that unlike the study by Tzelgov et al. (1996), no cross-script homophones were employed. All the stimuli were words in the script in which they were written. Native speakers of Japanese, all of whom were proficient bilinguals, were employed as participants in both parts of the experiment. Each participant performed the first part before the second part, so that for all the participants the results for the Japanese responses were not contaminated by any prior responding in English. The results for the English responses serve primarily as a replication of those for the Japanese responses.

\section{METHOD}

\section{Participants}

Twenty-four Japanese-English bilinguals participated. There were 7 men and 17 women, whose ages ranged from 21 to 43 years $(M=27)$. They were paid $\$ 15$ each. Five participants lived in Japan at the time of testing; however, they had previously spent an average of 4.6 years in English-speaking countries. The remaining 19 participants resided in Colorado. Their length of stay in the U.S. ranged from 1 month to 10 years $(M=3.8$ years). There were 18 individuals who had taken the Test of English as a Foreign Language (TOEFL), and the average score was 548.

\section{Design and Materials}

The experiment consisted of two parts (Japanese and English responding), each with a 2 (Japanese word type block pair: LWs or TCTs) $\times 2$ (stimulus type: words or control) $\times 2$ (stimulus language: English or Japanese) design, using three colors of ink (i.e., green, blue, and red) for the stimuli. All independent variables were varied within subjects. Response times (RTs) to name the color of ink of each stimulus set were measured.

All the stimuli were presented on $5 \times 8$ in. index cards. On a given card, nine handwritten letter strings were presented in lowercase for English and Katakana (LWs from English) and Hiragana (TCTs) for Japanese. Three types of control stimulus cards in colored bullets were also constructed so that the number of bullets in a string matched the number of characters in a word for each stimulus language (see Table 1). For example, the English control stimulus string for blue had four colored bullets, whereas the corresponding Katakana control stimulus string for ブルー had three colored bullets, and the corresponding Hiragana control stimulus string for あお had two colored bullets. All the stimulus words were incongruent color words that named the ink colors used in the experiment.

Under each orthography of English, Katakana, and Hiragana, a block of 18 cards ( 9 control cards and 9 word cards) was prepared. On each card, each of the three ink colors appeared three times, but never twice in a row. At the same time, the color terms (or corresponding sets of bullets) appeared three times each and no more than twice in a row. (No constraint was imposed concerning which of the six possible incongruent color-word combinations were employed. Across the 9 word cards, each combination occurred from 10 to 17 times.) Each card, therefore, presented nine sets of bullets (control) or color words arranged in a vertical column, using one of the three orthographies. For the control stimuli, the strings that matched the orthography in the block were used.

In a given pair of successive blocks, only two types of orthography, English and one of the two types of Japanese orthography, were presented, and when responding in Japanese the participants were asked to respond in either LWs or TCTs, whichever matched the Japanese orthography of the given pair of blocks. For each part of the experiment (Japanese responding and English responding), each participant was exposed to four blocks in total, one pair of blocks with LWs and the other with TCTs.

Word (W) and control (C) cards appeared pseudorandomly for each orthographic condition among the 18 cards in a block. Half of the participants were exposed to one sequence of 18 cards for each

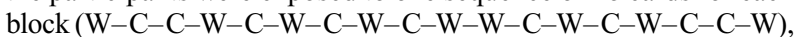
whereas the other half of the participants were exposed to the inverse sequence $(\mathrm{C}-\mathrm{W}-\mathrm{W}-\mathrm{C}-\mathrm{W}-\mathrm{C}-\mathrm{W}-\mathrm{C}-\mathrm{W}-\mathrm{C}-\mathrm{C}-\mathrm{W}-\mathrm{C}-\mathrm{W}-$ $\mathrm{C}-\mathrm{W}-\mathrm{W}-\mathrm{C})$. The color words used on a given card, in addition to their order and the order of the ink colors on the card, were the same for each of the three orthographic conditions. The pair of blocks for the LWs and that for the TCTs occurred in an order counterbalanced across participants. Likewise, the order of stimulus language (English first or Japanese first) within a pair of blocks was counterbalanced across participants. The three types of counterbalancing (for stimulus type, for Japanese word type block pair, and for stimulus language) were all fully crossed, yielding a group of 8 participants to complete a counterbalanced set.

\section{Procedure}

The participants were tested individually in 50-min sessions. At the beginning of the experiment, only general instructions were given. These included the following: (1) how many blocks (four) would be presented in the first part of the experiment and how many stimulus cards (18) would be in each block, (2) that the participants would see either words or colored bullets on a given card, and (3) that the words would be written either in English or in Japanese. No mention was made of Katakana or Hiragana orthographies. After the general instructions, the instructions for the response language were given for each block of trials; the participants were asked to respond in either LWs or TCTs. One Japanese word type was used in the first two blocks, and the other in the last two blocks. The participants were told or reminded of the specific Japanese word type before a given block began. After responses in either LWs or TCTs in the first part of the experiment, the same procedure was repeated for the second part, except that all responses were in English, with the pairs of blocks in the same order for both parts of the experiment. Immediately before the second part, the participants filled out a questionnaire about language background, which took them approximately $5 \mathrm{~min}$ to complete.

The experimenter presented each stimulus card one at a time, while checking a score sheet that contained the correct responses. The experimenter, however, could not see the front of the cards and so was blind to the conditions that a participant was exposed to. A stopwatch was used to record the RTs (in seconds) required for each participant to complete each card. Any errors were marked on the score sheets.

\section{RESULTS}

The RTs were analyzed separately for Japanese and English responding. In each case, a $2 \times 2 \times 2$ repeated measures analysis of variance was conducted, with Japanese word type block pair (LWs or TCTs), stimulus lan- 
guage (English or Japanese), and stimulus type (words or control) as factors. Also, an analysis restricted to the between-language conditions was conducted in each case, and an analysis comparing response languages was conducted that was restricted to the between-language conditions. For all of these analyses, the effect of stimulus type was used as an index of the Stroop effect.

\section{Japanese Responding}

Error rate was minimal; only 11 participants made errors. The mean percentage of cards with one or more errors was $3.9 \%$. To mitigate the problem of outliers in the RTs, all RTs over 2.5 standard deviations from the mean for a given condition were truncated to exactly 2.5 standard deviations from the mean; there were 40 outliers in total $(2.3 \%)$.

The results are summarized in Table 2. An overall Stroop effect was evident because responses to words $(5.14 \mathrm{sec})$ were significantly slower than those to the control bullets $\left[4.30 \mathrm{sec} ; F(1,23)=183.59, M S_{\mathrm{e}}=0.18\right.$, $p<.001]$. In addition, the participants were slower overall when the Japanese word type block pair consisted of LWs $(5.06 \mathrm{sec})$ than when it consisted of TCTs [4.37 sec; $\left.F(1,23)=87.30, M S_{\mathrm{e}}=0.26, p<.001\right]$, perhaps in part because of the greater frequency in the language of the TCTs. Although there was no overall difference between English and Japanese stimuli, the effect of stimulus language depended on Japanese word type block pair $\left[F(1,23)=7.09, M S_{\mathrm{e}}=0.11, p<.05\right]$. In particular, responses to English stimuli were faster than those to Japanese stimuli with the TCT block pair (English, $4.27 \mathrm{sec}$; Japanese, $4.47 \mathrm{sec}$ ), but not with the LW block pair (English, $5.09 \mathrm{sec}$; Japanese, $5.03 \mathrm{sec}$ ). Also importantly, the Stroop effect was larger overall for the LW block pair (words, $5.55 \mathrm{sec}$; control, $4.58 \mathrm{sec}$ ) than for the TCT block pair [words, $4.72 \mathrm{sec}$; control, $4.02 \mathrm{sec} ; F(1,23)=$ $18.90, M S_{\mathrm{e}}=0.05, p<.001$.]

The difference between the magnitude of the Stroop effect for LW and for TCT block pairs tended to be greater with English stimuli than with Japanese stimuli; however, the three-way interaction of stimulus language, Japanese word type block pair, and stimulus type did not reach statistical significance $\left[F(1,23)=2.57, M S_{\mathrm{e}}=0.08, p>.10\right]$.

Of greatest theoretical interest is the magnitude of the Stroop effect between languages, especially given findings from earlier studies (e.g., Brauer, 1998) that the Stroop effect for fluent bilinguals is minimal between languages that do not have a similar orthography. A separate analysis was therefore conducted on only the English stimuli. This analysis provided statistical evidence that the Stroop effect was significant overall and that it was significantly larger for the block pair with LWs (phonologically similar to the English words) than for the block pair with TCTs (phonologically dissimilar to the English words). Specifically, the main effect of stimulus type was significant $\left[F(1,23)=137.35, M S_{\mathrm{e}}=\right.$ $0.11, p<.001]$, as were the main effect of Japanese word type block pair $\left[F(1,23)=121.69, M S_{\mathrm{e}}=0.13, p<\right.$ $.001]$ and, importantly, the interaction between stimulus type and Japanese word type block pair $[F(1,23)=14.72$, $\left.M S_{\mathrm{e}}=0.07, p<.001\right]$.

Separate $t$ tests assessing the magnitude of the Stroop effect were significant for each combination of stimulus language and Japanese word type block pair $[t(23) \geq$ $6.86, p<.001$, in each case].

\section{English Responding}

Error rate was minimal; only 10 participants made errors. The mean percentage of cards with one or more errors was $4.1 \%$. There were 36 outliers in total $(2.1 \%)$, and these were truncated in the same manner as with Japanese responding.

The results are summarized in Table 3. An overall Stroop effect was evident because responses to word stimuli $(4.74 \mathrm{sec})$ were significantly slower than those to control stimuli $\left[4.02 \mathrm{sec} ; F(1,23)=242.54, M S_{\mathrm{e}}=0.10\right.$, $p<.001]$. Also, the participants were slower overall when the Japanese word type block pair consisted of LWs $(4.44 \mathrm{sec})$ than when it consisted of TCTs [ $4.33 \mathrm{sec}$; $\left.F(1,23)=6.21, M S_{\mathrm{e}}=0.10, p<.05\right]$. Furthermore, responses were slower overall to English $(4.43 \mathrm{sec})$ than to Japanese $(4.33 \mathrm{sec})$ stimuli $\left[F(1,23)=8.52, M S_{\mathrm{e}}=0.06\right.$,

Table 2

Japanese Responding: Mean Response Times (in Seconds) and Standard Errors of the Means as a Function of Japanese Word Type Block Pair (LWs or TCTs), Stimulus Language (English or Japanese), and Stimulus Type (Words or Control)

\begin{tabular}{|c|c|c|c|c|c|}
\hline \multirow{3}{*}{$\begin{array}{c}\text { Japanese Word Type } \\
\text { Block Pair }\end{array}$} & \multirow{3}{*}{$\begin{array}{l}\text { Stimulus } \\
\text { Type }\end{array}$} & \multicolumn{4}{|c|}{ Stimulus Language } \\
\hline & & \multicolumn{2}{|c|}{ English } & \multicolumn{2}{|c|}{ Japanese } \\
\hline & & $M$ & $S E$ & $M$ & $S E$ \\
\hline \multirow[t]{3}{*}{ LWs (Katakana) } & Words & 5.60 & .14 & 5.50 & .15 \\
\hline & Control & 4.59 & .11 & 4.56 & .14 \\
\hline & Difference (Stroop effect) & 1.01 & & 0.94 & \\
\hline \multirow[t]{3}{*}{ TCTs (Hiragana) } & Words & 4.57 & .13 & 4.87 & .15 \\
\hline & Control & 3.97 & .12 & 4.07 & .13 \\
\hline & Difference (Stroop effect) & 0.60 & & 0.80 & \\
\hline
\end{tabular}

Note- "Between" refers to interference between two different languages (i.e., the stimulus and response languages differ), and "within" refers to interference within a single language (i.e., the stimulus language and response language are the same). LW, loan word; TCT, traditional color term. 
Table 3

English Responding: Mean Response Times (in Seconds) and Standard Errors of the Means as a Function of Japanese Word Type Block Pair (LWs or TCTs), Stimulus Language (English or Japanese), and Stimulus Type (Words or Control)

\begin{tabular}{|c|c|c|c|c|c|}
\hline \multirow{3}{*}{$\begin{array}{c}\text { Japanese Word Type } \\
\text { Block Pair }\end{array}$} & \multirow{3}{*}{$\begin{array}{l}\text { Stimulus } \\
\text { Type }\end{array}$} & \multicolumn{4}{|c|}{ Stimulus Language } \\
\hline & & \multicolumn{2}{|c|}{ English } & \multicolumn{2}{|c|}{ Japanese } \\
\hline & & $M$ & $S E$ & $M$ & $S E$ \\
\hline \multirow[t]{3}{*}{ LWs (Katakana) } & Words & 4.88 & .13 & 4.85 & .13 \\
\hline & Control & 3.97 & .12 & 4.07 & .12 \\
\hline & Difference (Stroop effect) & 0.91 & & 0.78 & en) \\
\hline \multirow[t]{3}{*}{ TCTs (Hiragana) } & Words & 4.84 & .12 & 4.42 & .13 \\
\hline & Control & 4.05 & .10 & 4.00 & .13 \\
\hline & Difference (Stroop effect) & 0.79 & & 0.42 & en) \\
\hline
\end{tabular}

Note- "Between" refers to interference between two different languages (i.e., the stimulus and response languages differ), and "within" refers to interference within a single language (i.e., the stimulus language and response language are the same). LW, loan word; TCT, traditional color term.

$p<.01]$. And the Stroop effect was larger overall for English stimuli (words, $4.86 \mathrm{sec}$; control, $4.01 \mathrm{sec}$ ) than for Japanese stimuli [words, $4.63 \mathrm{sec}$; control, $4.03 \mathrm{sec}$; $\left.F(1,23)=21.90, M S_{\mathrm{e}}=0.03, p<.001\right]$. In addition, the effect of stimulus language depended on Japanese word type block pair: Responses to English stimuli were slower than those to Japanese stimuli with the TCT block pair (English, $4.44 \mathrm{sec}$; Japanese, $4.21 \mathrm{sec}$ ), but not with the LW block pair [English, $4.42 \mathrm{sec}$; Japanese, $4.46 \mathrm{sec}$; $\left.F(1,23)=16.62, M S_{\mathrm{e}}=0.05, p<.001\right]$. Importantly, the Stroop effect was larger overall for the LW block pair (words, $4.86 \mathrm{sec}$; control, $4.02 \mathrm{sec}$ ) than for the TCT block pair [words, $4.63 \mathrm{sec}$; control, $4.02 \mathrm{sec} ; F(1,23)=$ 28.04, $\left.M S_{\mathrm{e}}=0.02, p<.001\right]$.

The difference between the magnitudes of the Stroop effect for the LW and the TCT block pairs was larger with Japanese stimuli than with English stimuli. Alternatively, the difference between the magnitudes of the Stroop effect with the English stimuli and with the Japanese stimuli was larger for the TCT block pair than for the LW block pair. The three-way interaction of stimulus language, Japanese word type block pair, and stimulus type was significant $\left[F(1,23)=4.91, M S_{\mathrm{e}}=0.04, p<.05\right]$.

Of greatest theoretical interest is the magnitude of the Stroop effect between languages. A separate analysis was conducted that was restricted to the Japanese stimuli. This analysis provided statistical evidence that the Stroop effect was significant overall and was significantly larger for the block pair with LWs than for the block pair with TCTs. The main effect of stimulus type was significant $\left[F(1,23)=125.89, M S_{\mathrm{e}}=0.07, p<\right.$ $.001]$, as were the main effect of Japanese word type block pair $\left[F(1,23)=15.99, M S_{\mathrm{e}}=0.09, p<.001\right]$ and, most important, the interaction between stimulus type and Japanese word type block pair $[F(1,23)=40.15$, $\left.M S_{\mathrm{e}}=0.02, p<.001\right]$.

Separate $t$ tests assessing the magnitude of the Stroop effect were significant for each combination of stimulus language and Japanese word type $[t(23) \geq 8.03, p<$ .001 , in each case].

\section{Comparing Japanese and English Responding}

In an analysis comparing Japanese and English responding restricted to the between-language conditions, all main effects and interactions were significant $(F>7.30$, $p<.05$ ), except the three-way interaction of response language, Japanese word type block pair, and stimulus type $[F(1,23)<1]$. Most important, the interaction of Japanese word type block pair and stimulus type was significant $\left[F(1,23)=38.04, M S_{\mathrm{e}}=0.05, p<.001\right]$, documenting the larger Stroop effect with LWs (words, $5.22 \mathrm{sec}$; control, $4.33 \mathrm{sec}$ ) than with TCTs (words, $4.49 \mathrm{sec}$; control, $3.99 \mathrm{sec}$ ). The lack of the three-way interaction shows that this pattern did not depend on response language.

\section{DISCUSSION}

Despite the fact that English and Japanese are dissimilar languages, strong evidence was found in both parts of the present experiment for between-language interference. This interference seems to be based, in part, on phonological similarity between the color words in the two languages. Regardless of response language, there was significantly more interference between English and Japanese when the color terms were phonologically similar. An examination restricted to the cross-language trials for both response languages provided strong evidence that the Stroop effect was larger for the LWs than for the TCTs in each case. Because the LWs and the TCTs are equally dissimilar from English in terms of their orthography but only the LWs are similar to English phonologically, this finding strongly implicates the involvement of unintentional phonological processing in lexical access. Although orthography can play a role in the Stroop task, the relative contributions of orthography and phonology were not compared in the present study. Holding orthography essentially constant does nevertheless strongly demonstrate an effect of phonological processing independent of orthography.

The role of phonology in lexical access has been quite controversial. Some investigators have argued that phono- 
logical codes necessarily mediate lexical access (see Frost, 1998, for a summary), on the basis of evidence from semantic categorization (e.g., Van Orden, 1987), backward visual masking (e.g., Perfetti, Bell, \& Delaney, 1988), primed naming (e.g., Lukatela \& Turvey, 1994), and Stroop (e.g., Spinks, Liu, Perfetti, \& Tan, 2000; Tzelgov et al., 1996) tasks. In contrast, other investigators have not found phonological effects (e.g., Damian \& Martin, 1998; Davelaar, Coltheart, Besner, \& Jonasson, 1978). For example, in a picture-word interference task, Damian and Martin found an effect of distractors semantically related to the picture to be named (e.g., the word pear for the picture of an apple) but no comparable effect of distractors that were homophones of words semantically related to the picture (e.g., the word pair for the picture of an apple). Thus, Damian and Martin concluded that access to word meaning does not always involve phonology. Note that the pictures in their task were analogous to the colors in our Stroop task and that the homophone distractors in their task were analogous to the LWs in our task. Although Damian and Martin did not find effects of such distractors, we did find effects of the LWs in our study. Thus, our results are consistent with the opposite conclusion-namely, that access to word meaning does necessarily involve phonology, even when word access is unintentional.

One crucial difference between our procedure and that of Damian and Martin (1998) that may account for the discrepancy between the two sets of findings is that the target to be named and the written distractor word were semantically dissimilar in the study of Damian and Martin (e.g., the picture of an apple and the word pair) but were semantically similar in the present study (e.g., the ink color red and the LW ブルー meaning blue). The study by Spinks et al. (2000), in which Chinese characters were used as stimuli, provides two types of support for the contribution of semantic similarity to interference in lexical access. First, actual color words yielded significantly greater Stroop interference than did color-word homophones. Second, semantic associates that were not phonologically similar to color words yielded significant interference as well. However, the findings by Spinks et al. also suggest that phonological similarity does not necessarily need to be coupled with semantic similarity to yield Stroop interference. They found that interference by color-word homophones was statistically significant, despite the lack of semantic similarity. Likewise, Tzelgov et al. (1996) found that interference by cross-script homophones was always significant when the homophones sounded like words in the participant's L1, despite the fact that the homophones were nonwords in the language in which they were printed. However, Tzelgov et al. did not find significant interference when the cross-script homophones sounded like words in the participant's L2 unless the participant was aware that the stimuli had meaning in L2. Furthermore, on the basis of their Experiment 6, Tzelgov et al. postulated different processing mechanisms for the Stroop effect found with cross-script homophones and with regular words. Evidence for phonological processing of cross-script homophones is not as surprising as evidence for phonological processing of regular words, because the alternate direct access route from the visual pattern to meaning is unavailable with cross-script homophones but is available with regular words. In the present study, in which regular words in their familiar script, rather than cross-script homophones, were used, interference was found for both English (L2) and Japanese (L1) stimuli under both English and Japanese responding. Thus, our results confirm and extend the conclusions of Tzelgov et al.

In the present study, in which proficient bilingual speakers were employed, between-language Stroop interference was found to be large in both experiments when LWs and Katakana were employed. In fact, betweenlanguage interference was as large as within-language interference when the colors of these words were named in Japanese. This finding seems inconsistent with previous results from highly proficient bilingual speakers of dissimilar language pairs (e.g., Chinese-English and EnglishGreek; Brauer, 1998). Instead, it resembles more strongly the previous findings from highly proficient bilingual speakers of similar language pairs (e.g., English-German and German-English; Brauer, 1998). These results imply that orthographically dissimilar languages containing words that are phonologically similar may be processed in the same way as similar languages. Furthermore, these results imply that the multiple access model, which includes all three links in Figure 1, is appropriate for highly proficient bilinguals of orthographically dissimilar language pairs in some cases - namely, when there is phonological similarity between matching words in the two languages.

Thus, the present results support the existence for highly proficient bilinguals of direct links connecting matching words in the two languages (i.e., the A link in Figure 1, such as that connecting blue in English with ブルー in Katakana) even for orthographically dissimilar languages if the matching words are similar phonologically (as well as semantically). However, even though the matching words that are phonologically similar (e.g., blue and ブルー) may have direct links for a given highly proficient bilingual individual, other matching words in the same languages may not have such direct links for the same individual if the matching words are not phonologically similar (e.g., bread in English and パン [pan] in Katakana may not have direct links). Thus, the multiple access model may not apply uniformly to all matching words for a given highly proficient bilingual individual. More generally, the operative links connecting the two lexicons for any bilingual speakers may not be the same for all matching words and may depend on the phonological similarity of the matching words.

The possibility that the existence and strength of a link connecting two lexicons varies across specific matching words can be understood using the theoretical framework of a network model, such as that proposed by Cohen, 
Dunbar, and McClelland (1990) for the Stroop task, in which there are separate nodes and connecting pathways for different words and these vary in strength. Such models have been recently criticized by Roelofs (2003) because they are unable to give a complete account of the time course of the Stroop phenomenon. Roelofs proposed an alternative hybrid model that contains a production rule system as well as spreading activation. The withinand between-language bilingual Stroop effects are explained in Roelofs's model by the same theoretical mechanisms as those employed to account for response set effects (i.e., larger Stroop effects when the color words are from the set of ink colors used in the experiment; e.g., Klein, 1964) - namely, by assuming that attention is selectively allocated to potential responses. However, it is not clear that such a mechanism could explain our finding that between-language interference can be as large as within-language interference when there is phonological similarity between the words in the two languages, because the words in the alternate language would not be potential responses even when they are phonologically similar to the response set members. Our results, therefore, not only challenge current models of bilingual word processing, but also challenge current models of the Stroop effect.

\section{REFERENCES}

Brauer, M. (1998). Stroop interference in bilinguals: The role of similarity between the two languages. In A. F. Healy \& L. E. Bourne, Jr. (Eds.), Foreign language learning: Psycholinguistic studies on training and retention (pp. 317-337). Mahwah, NJ: Erlbaum.

Chen, H.-C., \& Ho, C. (1986). Development of Stroop interference in Chinese-English bilinguals. Journal of Experimental Psychology: Learning, Memory, \& Cognition, 12, 397-401.

Cohen, J. D., Dunbar, K., \& McClelland, J. L. (1990). On the control of automatic processes: A parallel distributed processing account of the Stroop effect. Psychological Review, 97, 332-361.

Damian, M. F., \& Martin, R. C. (1998). Is visual lexical access based on phonological codes? Evidence from a picture-word interference task. Psychonomic Bulletin \& Review, 5, 91-95.

DavelaAr, E., Coltheart, M., Besner, D., \& Jonasson, J. T. (1978). Phonological recoding and lexical access. Memory \& Cognition, 6, 391-402.

DYER, F. N. (1971). Color-naming interference in monolinguals and bilinguals. Journal of Verbal Learning \& Verbal Behavior, 10, $297-$ 302.

FANG, S. P., Tzeng, O. J. L., \& Alva, L. (1981). Intralanguage vs. interlanguage Stroop effects in two types of writing systems. Memory \& Cognition, 9, 609-617.

Feldman, L. B., \& TuRveY, M. T. (1980). Words written in Kana are named faster than the same words written in Kanji. Language \& Speech, 23, 141-147.

FRANCIS, W. S. (1999). Cognitive integration of language and memory in bilinguals: Semantic representation. Psychological Bulletin, 125, 193-222.
Frost, R. (1998). Towards a strong phonological theory of visual word recognition: True issues and false trails. $\underline{\text { Psychological Bulletin, } \mathbf{1 2 3}}$, 71-99.

KLEIN, G. S. (1964). Semantic power measured through the interference of words with color-naming. American Journal of Psychology, 77, 576-588.

KoLERS, P. A. (1966). Interlingual facilitation of short-term memory. Journal of Verbal Learning \& Verbal Behavior, 5, 314-319.

Kroll, J. F., Michael, E., \& Sankaranarayanan, A. (1998). A model of bilingual representation and its implications for second language acquisition. In A. F. Healy \& L. E. Bourne, Jr. (Eds.), Foreign language learning: Psycholinguistic studies on training and retention (pp. 365-395). Mahwah, NJ: Erlbaum.

Kroll, J. F., \& STEWART, E. (1994). Category interference in translation and picture naming: Evidence for asymmetric connections between bilingual memory representations. Journal of Memory \& Language, 33, 149-174.

LuKatela, G., \& Turvey, M. T. (1994). Visual lexical access is initially phonological: 2 . Evidence from phonological priming by homophones and pseudohomophones. Journal of Experimental Psychology: General, 123, 331-353.

MACLEOD, C. M. (1991). Half a century of research on the Stroop effect: An integrative review. Psychological Bulletin, 109, 163-203.

MäGISTE, E. (1984). Stroop tasks and dichotic translation: The development of interference patterns in bilinguals. Journal of Experimental Psychology: Learning, Memory, \& Cognition, 10, 304-315.

MORIKAWA, Y. (1981). Stroop phenomena in the Japanese language: The case of ideographic characters (Kanji) and syllabic characters (Kana). Perceptual \& Motor Skills, 53, 67-77.

Perfetti, C. A., Bell, L. C., \& Delaney, S. M. (1988). Automatic (prelexical) phonetic activation in silent word reading: Evidence from backward masking. Journal of Memory \& Language, 27, 59-70.

Posner, M. I., \& SNydER, C. R. R. (1975). Attention and cognitive control. In R. L. Solso (Ed.), Information processing and cognition: The Loyola symposium (pp. 55-85). Hillsdale, NJ: Erlbaum.

Potter, M. C., So, K.-F., Von Eckardt, B., \& Feldman, L. B. (1984). Lexical and conceptual representation in beginning and more proficient bilinguals. Journal of Verbal Learning \& Verbal Behavior, 23, 23-38.

PRESTON, M. S., \& LAMBERT, W. E. (1969). Interlingual interference in a bilingual version of the Stroop color-word task. Journal of Verbal Learning \& Verbal Behavior, 8, 295-301.

RoELOFS, A. (2003). Goal-referenced selection of verbal action: Modeling attentional control in the Stroop task. Psychological Review, 110, 88-125.

Spinks, J. A., LiU, Y., Perfetti, C. A., \& Tan, L. H. (2000). Reading Chinese characters for meaning: The role of phonological information. Cognition, 76, B1-B11.

Stroop, J. R. (1935). Studies of interference in serial verbal reactions. Journal of Experimental Psychology, 18, 643-662.

TzElgOv, J., HENIK, A., SNEG, R., \& BARUCH, O. (1996). Unintentional word reading via the phonological route: The Stroop effect with crossscript homophones. Journal of Experimental Psychology: Learning, Memory, \& Cognition, 22, 336-349.

VAN ORDEN, G. C. (1987). A ROWS is a ROSE: Spelling, sound, and reading. Memory \& Cognition, 15, 181-198.

(Manuscript received May 2, 2003; revision accepted for publication January 4, 2004.) 